\title{
Música e política, passado e presente: trânsitos atlânticos das canções escravas
}

\author{
Cecília da Silva Azevedo ${ }^{1}$
}

ABREU, Martha. Da senzala aos palcos: Canções escravas e racismo nas Américas , 1870-1930. Campinas, Ed. Unicamp, 2017.

Resenha recebida em: $26 / 11 / 2018$

Resenha aprovada em: 08/12/2018

Num formato ainda raro entre nós, este livro digital que integra a Coleção História Illustrada explora as possibilidades que esta mídia oferece de conjugação de texto, som e imagem. Além das mais de 200 fotos, ilustrações de partituras, anúncios de espetáculos, notícias de jornais - o e-book traz dezenas de fonogramas e alguns vídeos com gravações de canções e espetáculos musicais do início do século XX que permitem ao leitor/ouvinte uma extraordinária experiência de interação com as fontes que sustentam o empreendimento historiográfico. A narrativa é leve, mas muito potente, favorecendo a recepção do trabalho por um público mais amplo que o acadêmico. ${ }^{2}$

A autora é Professora Titular de História das Américas da Universidade Federal Fluminense e consagrada pesquisadora da cultura popular, música negra, memória da escravidão e relações raciais no pós-abolição nas Américas. Além de inúmeros livros e artigos, já havia produzido, também de forma pioneira, vários vídeos de pesquisa que nos fazem refletir sobre novos suportes para o discurso historiográfico e ensino de História.

A pesquisa se situa entre as décadas de 1870 e 1930, contexto da emergência e difusão das chamadas canções escravas no mercado cultural em diferentes pontos do Atlântico Negro - conforme concebido por Paul Giroy ${ }^{3}$-, na esteira dos fluxos já seculares de mercadorias e pessoas que se intensificaram nas últimas décadas do século XIX e primeiras décadas do XX. Não por mera coincidência, enquanto ocorria um novo

\footnotetext{
${ }^{1}$ Professora aposentada do Departamento de História da Universidade Federal Fluminense. Professora do Programa de Pós-Graduação em História da Universidade Federal Fluminense. Email: ceciliasa@uol.com.br

${ }^{2}$ Foi produzido excelente filme para divulgação do livro e uso nas escolas. https://www.youtube.com/watch?v=agZPb-uEVto
}

${ }^{3}$ GIROY, Paul. O Atlântico Negro, modernidade e dupla consciência. São Paulo/Rio de Janeiro. Editora 34/Universidade Cândido Mendes, Centro de Estudos Afro-Asiáticos, 2001.

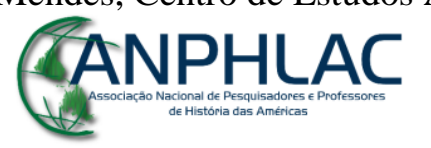


avanço colonial sobre a África, a música negra era admitida em ambientes da elite branca na Europa e nas Américas.

Dividido em duas partes - "Trânsitos do Atlântico Negro" e "Canções Escravas no Brasil", o livro persegue o tempo todo a dimensão transnacional das relações raciais nas Américas, através dos significados sociais e políticos associados à música negra. Acompanha, assim, a circulação de artistas, cantores, dançarinos e compositores de diferentes ritmos e estilos musicais que marcaram presença nos espetáculos musicais, teatros de revista, circo e na nascente indústria fonográfica e de edição de partituras. Desse modo, ao lado das valsas e polcas, tocava-se e dançava-se cakewalk, rag, lundu, maxixe, "tango negro" em cidades como Nova York, Buenos Aires, Havana e Rio de Janeiro. Uma paisagem cultural muito mais plural e complexa do que as descrições mais correntes sobre os padrões de modernidade em ascensão naquele período permitem imaginar. Além das modas europeias, a chamada Belle Époque, no Rio de Janeiro e outros pontos das Américas, abriu espaço, com pesadas restrições e enquadramentos como bem sublinha a autora, para canções que habitavam o mundo da escravidão. Nos teatros e salões frequentados pela elite branca ouvia-se ecos de uma diáspora que ainda atravessa gerações e continentes.

A visibilidade que as canções dos descendentes de escravos nas Américas alcançou no mundo do entretenimento deve ser articulada à necessidade de conceber novas identidades e projetos de nação no pós-abolição. E um dos pontos cruciais do livro é mostrar que há muito mais paralelismos que contrastes entre EUA e Brasil nas representações racistas construídas de modo a justificar a inferiorização e exclusão social dos negros. As músicas e personagens negros carregavam estereótipos fortíssimos e muito semelhantes ligados à sensualidade, alegria, irracionalidade e passividade infantis expressas através dos ritmos, figurinos, maquiagem e movimentos corporais - requebros e sapateios -, o que redundava numa ridicularização e estigmatização dos corpos e da cultura negra. Memórias, identidades e formas de resistência dos escravos, transformados em espetáculo, traduziam uma nova forma de espoliação e subjugação. O racismo, que também então era expresso em linguagem médica e legal, estabeleceu-se como o pilar central da construção cultural e política do nosso ocidente moderno, onde queria se incluir o Brasil e outras sociedades americanas depois de abolida a escravidão.

\section{GANPHLAC}


Ao longo do livro vemos e ouvimos evidências desse fluxo cultural intenso e multidirecional. Uma das mais encantadoras experiências que o livro nos reserva é ouvir os fonogramas do "The Entertainer”, de Scott Joplin, e “Odeon”, de Ernesto de Nazareth, um depois do outro. A incrível semelhança dessas composições já seria convincente o suficiente, mas o panorama desse intenso intercâmbio musical ganha maior nitidez e riqueza com a associação de outros casos e fontes.

A partir de uma crônica e relatos de jornais dos primeiros anos do século XX sobre a presença no Rio de Janeiro do cakewalk, a dança de escravos das plantations que virara febre nos EUA, vemos imagens retratando negros e brancos em movimentos característicos dessa dança hilariante pelas possibilidades de paródia que oferece: escravos que imitam senhores; brancos que imitam negros nos salões; negros que imitam brancos imitando negros...

Numa clara demonstração das brutais contradições dos processos sociais e políticos, índices de popularização do cakewalk nos musicais da Broadway em Nova York na década de 1890 coincidem com a imposição do regime de segregação racial conhecido como Jim Crow, significativamente nome de um personagem dos minstrel shows que faziam sucesso desde 1830.

No Brasil os cakewalks dialogavam com gêneros "nacionais" que também atraíam a nascente indústria fonográfica. Uma fonte extraordinária utilizada no livro são catálogos das editoras e álbuns de família com partituras para piano. O rol das canções, em suas múltiplas e complexas denominações e associações - modinhas, lundus, habaneras, mazurcas, tangos, choros, caretetês, fados, chulas, charlestons, foxtrotes e ragtimes demonstram o quanto os ritmos sincopados das canções escravas se irradiavam. Nas capas das partituras brasileiras via-se os mesmos traços grosseiros dos blackfaces em cenas que impressionam por seu forte cunho racista. Ao mesmo tempo, partituras de maxixes e “tangos brasileiros" eram vendidas nos EUA.

As Jazzbands, que seduziam um público sedento por signos de modernidade e também escandalizavam por sua sensualidade, faziam sucesso em Nova York, Paris e também em São Paulo e no Rio de Janeiro. Destaca-se o caso dos Oito Batutas, de Pixinguinha e outros músicos negros, como Donga, sempre associado ao primeiro samba "Pelo telefone", mas não às gravações pelo grupo de gêneros híbridos que dominavam os experimentos musicais das duas primeiras décadas do século XX.

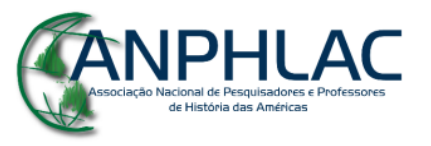


Nos teatros era maior a discriminação de atores e atrizes negras, preteridas em relação às mulatas. Cantores e dançarinas europeias e caribenhas muitas vezes encarnavam baianas ou outros tipos locais, como faria posteriormente Carmen Miranda, que pode ter produzido uma versão própria, mas não totalmente original, desse gênero. Nesse ambiente de racismo não institucionalizado mas intenso, é realmente digno de nota o surgimento de companhias e personagens como a Companhia Negra de Revistas de De Chocolat apresentando o espetáculo "Tudo Preto", em 1926, com Pixinguinha comandando a orquestra.

A partir daí, a autora, que em trabalhos anteriores já havia recuperado a presença de jongos, lundus e batuques em festas populares na capital do Império ao longo do século XIX, joga luz sobre os sentidos políticos que a música negra adquire no período que antecede e se segue à abolição, quando as possibilidades do exercício da cidadania pelos libertos entram em pauta.

Ao lado de uma verdadeira pedagogia do racismo, com personagens negros sendo apresentados num duplo registro depreciativo de exotismo, ingenuidade e resignação, por um lado, e malícia, lascívia, promiscuidade e primitivismo, por outro, Martha Abreu é capaz de enxergar tentativas de subversão levadas a cabo por artistas e músicos negros mesmo quando viviam e utilizavam personagens, enredos e máscaras estereotipadas.

Nesse sentido, são recuperadas trajetórias de artistas negros nascidos no mesmo período e que alcançaram sucesso nos palcos do Rio de Janeiro e Nova York e também através da indústria fonográfica: Eduardo das Neves, que se apresentava como "crioulo Dudu", e Bert Williams, que se dizia um "real coon". Ambos procuraram lidar e reformatar representações estigmatizantes dos negros valendo-se de inversões e ironias em suas apresentações em circos e vaudevilles.

A autora argumenta com argúcia que sentidos muito distintos e perturbadores emergem quando negros passam eles mesmos a viver blackfaces ou quando pintam o rosto de branco para interpretar personagens brancos. Seguindo o mesmo raciocínio, o sucesso do Jongo dos Sexagenários, que teria sido assistido por um público de 45 mil pessoas, figuras emblemáticas do Teatro de bonecos representando abolicionistas e pretos velhos espertos seduzindo "clarinhas" e iaiás não podem deixar de ser pensados como desafios mais ou menos sutis ao imaginário racista dominante.

\section{CANPHLAC}


Virando a lente para os EUA, ao lado dos famosos Uncle Tom e Uncle Remus, representações do escravo e do liberto como assexuados e dóceis a despeito do sofrimento, passam a povoar a cultura popular personagens que fogem a esses cânones. Sambo e John, por exemplo, podem também ser malandros e se aproximam muito do nosso Pai João.

A autora ainda dá voz a intelectuais negros e mestiços que se voltaram para o lugar da música negra na construção da nação no Brasil e nos EUA. WEB Dubois, com seu belíssimo Almas da Gente Negra, e as reflexões de Coelho Neto e André Rebouças deixam entrever que o legado da canção escrava foi reconhecido como fundamental muito antes que articulação entre o nacional e o popular fosse difundida por modernistas e pelo regime de Vargas.

O livro poderia alimentar discussões teóricas sobre a indústria cultural e a posição liminar do artista e ir adiante na análise de temas, letras e estruturas melódicas. As formas de encenação, circulação e recepção pelos diferentes públicos dos diversos espetáculos e produtos certamente oferecem ainda muitas possibilidades de desdobramento.

Mas a preocupação primordial de Martha Abreu, coerente com sua filiação à História Social da Cultura, foi pensar as conexões entre música e política, memória e identidade, passado e presente, compreendendo possibilidades e limites dos sujeitos em função de contextos em que viveram. O livro nunca pretendeu enxergar, no conjunto heteróclito de formas e ritmos, encaixes perfeitos como num quebra-cabeças. Por uma dupla razão: pela configuração híbrida, intercultural e necessariamente dinâmica do fenômeno estudado e pela natureza lacunar inescapável do conhecimento histórico que lhe concede um brilho tão especial.

Da história devemos desejar que seja o oposto do que Saramago disse sobre o diário. Não um modo incipiente de fazer ficção, que tanto declara quanto reserva, com a parte protegendo o todo, o simples ocultando o complexo. A autora deste livro não esconde os percalços da pesquisa. Muito menos seu rosto. Desde a introdução as perguntas que lança ao passado articulam-se ao seu engajamento nas políticas públicas no presente. No capítulo final, que inclui belíssimo trecho de um de seus filmes ${ }^{4}$,

\footnotetext{
${ }^{4}$ Jongos, Calangos e Folias. Música Negra, memória e poesia. Direção Geral: Hebe Matos e Martha Abreu. Labhoi/ Editora da UFF, 2007.
}

\section{CANPHLAC}


reafirma que os ritmos africanos de hoje não são simples ruídos ou sobrevivências do passado, mas formas de auto representação e luta por cidadania no presente. Uma história que não se escreve e vive a frio. E assim deve continuar a ser.

\section{GANPHLAC}

